COMUNICAÇÃO CIENTÍFICA

\title{
Comportamento de obtenção de Manihot esculenta Crantz (Euphorbiaceae), mandioca, por Cebus nigritus (Goldfuss) (Primates, Cebidae) como uma adaptação alimentar em períodos de escassez ${ }^{1}$
}

\author{
Gabriela Ludwig ${ }^{2}$; Lucas M. Aguiar ${ }^{2} \&$ Vlamir J. Rocha ${ }^{3}$ \\ 1 Contribuição número 1621 do Departamento de Zoologia, Universidade Federal do Paraná. \\ ${ }^{2}$ Laboratório de Biodiversidade, Conservação e Ecologia de Animais Silvestres, Departamento de Zoologia, Universidade \\ Federal do Paraná. Caixa Postal 19020, 81531-980 Curitiba, Paraná, Brasil. E-mail: gabiludwig@ufpr.br \\ 3 Pesquisa Florestal, Manejo Ambiental, Klabin S.A. Fazenda Monte Alegre, 84279-000 Lagoa, Paraná, Brasil.
}

\begin{abstract}
Acquisition behavior of Manihot esculenta Crantz (Euphorbiaceae), cassava, by Cebus nigritus (Goldfuss) (Primates, Cebidae) as a feeding adaptation on scarcity periods. This study reports the acquisition behavior and the frequency of consumption of cassava, Manihot esculenta Crantz, by Cebus nigritus (Goldfuss, 1809) in the wild during periods of drought. This exotic food item is subterraneous and therefore does not provide the clear visual stimuli for its detection, particularly in the case of organisms that are primarily visually-oriented such as primates.
\end{abstract}

KEY WORDS. Adaptation; animal behavior; capuchin monkey; diet; forest fragment.

RESUMO. Este trabalho relata o comportamento de obtenção e a freqüência de consumo de Manihot esculenta Crantz (mandioca) por Cebus nigritus (Goldfuss, 1809) em vida livre durante períodos de escassez. Este é um item alimentar subterrâneo e introduzido pelo homem, o qual não fornece estímulos visuais claros de sua existência, particularmente para animais que dependem primariamente da visão, tais como os primatas.

PALAVRAS-CHAVE. Adaptação; comportamento animal; dieta; fragmento florestal; macaco-prego.

Dentre os primatas da infraordem Platyrrhini (primatas do novo mundo), o gênero Cebus Erxleben, 1777, conhecido popularmente como macaco-prego, possui espécies com pronunciada destreza manual, cérebro grande e circunvoluncionado, alta sociabilidade, terrestrialidade e dieta onívora (Defler 1979, Freese \& Oppenheimer 1981, Auricchio 1995, Nowak 1999, Sussman 2000, Defler 2004). Tais características permitem ao gênero explorar recursos de maneira própria e que de outra forma não estariam disponíveis para os demais gêneros de primatas - a chamada capacidade "extra" de forrageio alimentar (Tomblin \& CRANFord 1994). Por exemplo, algumas espécies de macaco-prego na natureza utilizam ferramentas de modo espontâneo para acessar alimentos ou outros recursos subterrâneos, encapsulados ou introduzidos em outros tipos de substratos (Phillips 1998, Rocha et al. 1998, Fragaszy et al. 2004, Moura \& Lee 2004). Ainda, algumas populações conseguem utilizar-se de fontes alimentares provenientes do meio antrópico, tal como pomares e monoculturas, dentre estas: milho, cana-de-açúcar e até mesmo pinus (Galetti \& Pedroni 1994, Koehler \& Firkowski 1996, Rocha 2000, Siemers 2000, Defler 2004, Rocha-Mendes et al. 2005). Essa versatilidade no forrageamento alimentar do gênero Cebus pode em alguns casos o pré-adaptar frente aos efeitos da fragmentação, podendo sobreviver em habitats mínimos e fragmentados, desde que esses ambientes possuam acesso às plantações ao redor da mata (Rocha 2000). É nessa situação que esses primatas são vistos como pragas por produtores rurais ao atacarem os plantios (Rocha 2000, Defler 2004) e este impasse pode comprometer a conservação desses animais.

Portanto, diante dos fatos mencionados, este trabalho tem como objetivo relatar o comportamento de obtenção e a freqüência de consumo de raízes tuberosas de Manihot esculenta Crantz (mandioca) por Cebus nigritus (Goldfuss, 1809), um item alimentar subterrâneo, disponível somente em plantações fora da mata e introduzido no Sul do Brasil pela ação do homem (NASSAR 2002).

Cebus nigritus é a espécie de macaco-prego característica da Mata Atlântica ao longo da região Sul e parte da região Sudeste do Brasil. Ocorre desde o Estado do Rio Grande do Sul até os domínios do Rio Doce e do oceano Atlântico até a margem esquerda do Rio Paraná (Printes et al. 2001, SiLva Júnior 2002; 
Vilanova et al. 2005). Na região norte do Estado do Paraná, a espécie está entre os mamíferos mais facilmente encontrados em fragmentos florestais da região, onde passou a atacar principalmente os plantios de milho, a segunda maior monocultura do estado (PARANá 2001).

O consumo de milho e mandioca pela espécie foi registrado sistematicamente em grupos ocorrentes na Mata Doralice $\left(23^{\circ} 16^{\prime} \mathrm{S}\right.$ e $\left.51^{\circ} 03^{\prime} \mathrm{W}\right)$, um remanescente florestal de 170 ha de Floresta Estacional Semidecidual, no Município de Ibiporã-PR, porção alta do Rio Tibagi. As observações aqui registradas ocorreram durante um estudo de dieta e área de vida de um grupo que foi acompanhado durante $205 \mathrm{~h}$ entre outubro de 2001 a setembro de 2002. O comportamento de obtenção das raízes de mandioca foi registrado ad libitum (ALTMANn 1974) e a quantificação deste item na dieta dos animais ao longo do ano foi registrada através do método de freqüências de observações e análises de fezes. Para padronizar a freqüência com que cada item foi consumido do total encontrado na dieta, considerou-se como uma ocorrência cada vez que um item (animal ou vegetal) aparecia nas amostras, tanto as de observação direta do animal, quanto as fecais, e deste total obteve-se a freqüência de consumo da mandioca.

Para obtenção das raízes, os animais desciam ao solo e adentravam com postura quadrúpede nos plantios vizinhos a mata. Quando escolhido o vegetal, agachavam-se e começavam a cavar com as duas mãos junto à base da planta. Ao conseguirem acessar as raízes superficiais, os animais forçavam-as para cima como num sistema de alavancas até quebra-lás. Após, voltavam correndo na mesma postura para a mata com o alimento transportado em uma das mãos e/ou na boca, para então, consumi-lo nas árvores. Dos registros visualizados $(n=7)$, cinco consistiram de indivíduos sub-adultos que visitaram solitariamente o plantio e dois de uma fêmea adulta rodeada por dois e três juvenis, respectivamente. Estes observaram o processo de obtenção pelo adulto e posteriormente imitaram o que haviam visualizado, cavando a superfície do solo, porém sem sucesso de obtenção. Em todas as observações, pelo menos um indivíduo na borda da mata emitiu vocalizações de alta freqüência em contexto de alarme (OliveIra \& Ades 2004) devido à aproximação de cães domésticos ou pessoas, e, automaticamente, todos os animais retornavam à mata. Manihot esculenta foi disponível ao longo de todo o ano, no entanto, foi consumida ativamente apenas no final do outono e início do inverno (três e quatro registros, respectivamente). Isso resultou em baixa freqüência de consumo anual: $0,7 \%$ do total de itens da dieta.

Mesmo com oferta abundante e constante ao longo do ano, as raízes de mandioca só foram consumidas pelos primatas durante as épocas de menor oferta de alimentos dentro da mata (outono e inverno). Moura \& Lee (2004) também salientaram que a utilização de tubérculos de Thiloa glaucocarpa (Mart.) Eichl. (Combretaceae) por Cebus libidinosus Spix, 1823 através do ato de cavar foi devido à escassez natural de alimentos na Caatinga. Porém neste caso, os animais utilizaram ferramentas de pedra para acessar o alimento. Na Mata Doralice, essa relação custo- benefício pôde também ter influências da vulnerabilidade dos primatas ao ataque de predadores aéreos e de cães domésticos quando passam a ficar mais expostos nos plantios. Por exemplo, foi verificado durante este estudo a morte de um macho adulto de Cebus nigritus devido ao ataque simultâneo de três cães quando o indivíduo visitou um plantio de milho.

Devido ao seu conhecido hábito de forrageio terrestre, como por exemplo, a procura de artrópodes ou outros itens animais e vegetais no solo (Defler 1979, Rocha et al. 1998), o gênero Cebus pode apresentar-se como pré-disposto para a utilização de alimentos subterrâneos, que não disponibilizam estímulos visuais claros de suas existências, principalmente para animais que dependem primariamente da visão, tais como os primatas. Por conseqüência disto, estes recursos podem tornar-se inacessíveis para demais gêneros de primatas. Em resumo, parece que tanto as restrições e as imposições causadas pela escassez de alimento, quanto a existência do hábito terrestre, parecem juntos ser fatores chave para esta capacidade adicional de forrageio observada no gênero (ver discussões de Lee \& Moura 2005 e Visalberghi et al. 2005).

Por ser Manihot esculenta um alimento subterrâneo e além do mais, introduzido no ambiente natural de Cebus nigritus pela ação do homem e, portanto, até então desconhecido pela espécie e não pertencente ao seu repertório alimentar natural, podese aqui promover reflexões de como se deu o processo de cognição dos primatas para que eles assimilassem os tubérculos dessa planta como um alimento disponível. Tal processo poderia ter sido influenciado tanto diretamente quanto indiretamente pela própria ação da colheita humana? Outros animais de hábito terrestre ao forragearem nos plantios poderiam também fornecer informações diretas ou indiretas aos primatas? Ou propriedades inerentes aos próprios primatas foram suficientes para que eles reconhecessem esses alimentos? Experimentos em campo com populações de Cebus nigritus que ainda não tiveram contato com plantios daquela monocultura poderiam ajudar a responder tais questões.

Independente de como se deu esse processo, este trabalho ilustra uma adaptação comportamental e ecológica do gênero Cebus que o ajuda lidar com os efeitos da antropização e perda do habitat, impostos pelo mosaico de fragmentos e monoculturas que atualmente são corriqueiros ao longo da paisagem paranaense.

\section{AGRADECIMENTOS}

Ao CNPq, Universidade Federal do Paraná, Universidade Estadual de Londrina, Pedro Favoreto, a todos os funcionários da Fazenda Doralice, Nélio R. dos Reis, João M.D. Miranda, Fernando C. Passos e dois revisores anônimos.

\section{REFERÊNCIAS}

Altmann, J. 1974. Observational study of behavior: sampling methods. Behaviour, Leiden, 40: 227-267.

Auricchio, P. 1995. Primatas do Brasil. São Paulo, Terra Brasilis, $168 \mathrm{p}$.

Revista Brasileira de Zoologia 23 (3): 888-890, setembro 2006 
Defler, T.R. 1979. On the ecology and behavior of Cebus albifrons in eastern Colombia. Primates, Tokyo, 20: 475-502.

Defler, T.R. 2004. Primates of Colombia. Bogotá, Conservation International, 550p.

Fragaszy, D.; P. Izar; E. Visalberghi; E.B. Ottoni \& M.G. Oliveira. 2004. Wild capuchin monkeys (Cebus libidinosus) use anvils and stone pounding tools. American Journal of Primatology, Calgary, 64: 359-366.

Freese, C.H. \& J.R. OppenheImer. 1981. The capuchin monkeys, genus Cebus, p. 331-389. In: A.F. CoImBra-Filho \& R.A. Mittermeier (Ed.). Ecology and behavior of Neotropical primates. Rio de Janeiro, Academia Brasileira de Ciências, 496p.

Galetti, M. \& F. Pedroni. 1994. Seasonal diet of capuchin monkeys (Cebus apella) in a semideciduous Forest in southeast Brazil. Journal of Tropical Ecology, Cambridge, 10: 27-39.

Koenler, A. \& C. Firkowski. 1996. Descascamento de pinus por macaco-prego (Cebus apella). Floresta, Curitiba, 24(1-2): 6175.

LeE, P.C. \& A.C.A. Moura. 2005. Response to Visalberghi et al.: Terrestriality and tool use. Science, Washington, 308: 951.

Moura, A.C.A. \& P.C. Lee. 2004. Capuchin stone tool use in Caatinga Dry Forest. Science, Washington, 306: 1909.

NASSAR, N.M.A. 2002. Cassava, Manihot esculenta Crantz, genetic resources: origin of the crop, its evolution and relationships with wild relatives. Genetics and Molecular Research, Ribeirão Preto, 1 (4): 298-305.

NowAK, R.M. 1999. Walker's mammals of the world. Baltimore, The Johns Hopkins University Press, 1936p.

OliveirA, D.A. \& C. Ades. 2004. Long-distance calls in Neotropical Primates. Anais da Academia Brasileira de Ciências, Rio de Janeiro, 76 (2): 393-398.

PARANÁ. Secretaria de Agricultura e do Abastecimento. 2001. Acompanhamento da situação agropecuária do Paraná: Novembro/2001. Curitiba, Departamento de Economia Rural, 57p.

PHILliPs, K.A. 1998. Tool use in wild capuchin monkeys (Cebus albifrons trinitatis). American Journal of Primatology, Calgary, 46: 259-261.

Printes, R.C.; M.V.A. Liesenfeld \& L. Jerusalinsky. 2001. Alouatta guariba clamitans Cabrera, 1940: a new southern limit for the species and for neotropical primates. Neotropical Primates, Washington, 9 (3): 118-121.

Rocha, V.J. 2000. Macaco-prego, como controlar esta nova praga florestal? Floresta, Curitiba, 30 (1-2): 95-99.

Rocha, V.J.; N.R. Reis \& M.L. Sekiama. 1998. Uso de ferramentas por Cebus apella (Linnaeus) (Primates, Cebidae) para obtenção de larvas de coleóptera que parasitam sementes de Syagrus romanzoffianum (Cham.) Glassm. (Arecaceae). Revista Brasileira de Zoologia, Curitiba, 15 (4): 945-950.

Rocha-Mendes, F.; S.B. Mikich; G.V. Bianconi \& W.A. Pedro. 2005. Mamíferos do município de Fênix, Paraná, Brasil: etnozoologia e conservação. Revista Brasileira de Zoologia, Curitiba, 22 (4): 991-1002.

SIEMERS, B.M. 2000. Seasonal variation in food resource and forest strata use by brown capuchin monkeys (Cebus apella) in a disturbed forest fragment. Folia Primatologica, Basel, 71: 181-184.

SiLva Júnior, J.S. 2002. Taxonomy of capuchin monkeys, Cebus Erxleben, 1777. Neotropical Primates, Washington, 10 (1): 29.

Sussman, R.W. 2000. Primate ecology and social structure: New World monkey. Needham Heights, Pearson Custom Publishing, 207p.

Tomblin, D.C. \& J.A. Cranford. 1994. A ecological niche differences between Alouatta palliata and Cebus capucinus comparing feeding modes, branch use and diet. Primates, Tokyo, 35 (3): 265-274.

Vilanova, R.; J.S. Silva Júnior; C.E.V. Grelle; G. Marroig \& R. CerQUEIRA. 2005. Limites climáticos e vegetacionais das distribuições de Cebus nigritus e Cebus robustus (Cebinae, Platyrrhini). Neotropical Primates, Washington, 13 (1): 14-19.

Visalberghi, E.; D.M. Fragaszy; P. Izar \& E.B. Otonni. 2005. Terrestriality and tool use. Science, Washington, 308: 951.

Recebido em 24.I.2006; aceito em 28.VIII.2006. 